Atıf için / For Citation: G.İLGÜ BÜYÜK, S. ILICAN "Sol Jel Yöntemiyle Elde Edilen ZnO Filminin Yapısal, Morfolojik ve Optik Özelliklerine Erbiyum Katkısının Etkisi”, Süleyman Demirel Üniversitesi Fen Edebiyat Fakültesi Fen Dergisi, 14(2), 179-192, 2019.

\title{
Sol Jel Yöntemiyle Elde Edilen ZnO Filminin Yapısal, Morfolojik ve Optik Özelliklerine Erbiyum Katkısının Etkisi
}

\author{
Gonca İLGÜ BÜYÜK ${ }^{* 1}$, Saliha ILICAN ${ }^{2}$ \\ ${ }^{1}$ Eskişehir Teknik Üniversitesi, Fen Bilimleri Enstitüsü, Fizik Anabilim Dal,, 26470, Eskişehir, Türkiye \\ ${ }^{2}$ Eskişehir Teknik Üniversitesi, Fen Fakültesi, Fizik Bölümü, 26470, Eskişehir, Türkiye \\ * yazışllan yazar e-posta: goncailgu@gmail.com
}

(Alınış / Received: 18.02.2019, Kabul / Accepted: 02.07.2019, Yayımlanma / Published: 30.11.2019)

Özet: Katkısız ve Erbiyum (Er) katkılı çinko oksit (ZnO) filmleri sol jel spin kaplama yöntemi ile p-Si alttaşlar üzerine elde edilmiştir. $\mathrm{ZnO}$ filminin yapısal, morfolojik ve optik özellikleri üzerine Er katkısının etkisi sırasıyla, X-ışını kırınım cihazı, taramalı elektron mikroskobu (SEM) ve UV-vis spektrofotometresi kullanılarak araştırılmışıır. X-ışınları kırınımı (XRD) spektrumlarından, bütün filmlerin hekzagonal wurtzite yapıda ve zinkit fazda kristallendiği belirlenmiştir. Kristallenme boyutu, dislokasyon yoğunluğu, örgü parametreleri, kristal yapıdaki deformasyon ve gerilim gibi yapısal parametreler hesaplanmıştır. SEM görüntülerinden, film yüzeylerinin çatlaklar ve gözenekler olmadan iyi kaplanmış ve homojen olduğu görülmektedir. Ortalama tane boyutu, tane sınırları ve filmlerin yüzey durumlarının araştırılması için ImageJ programı kullanılmıştır. UV sprektrofotometresi ile optik ölçümler yapılmış ve optik bant aralığı diferansiyel yansıma ve Kubelka-Munk teorisiyle belirlenmiştir. Her iki yöntemden de, $\mathrm{ZnO}$ filminin optik band değerinin Er katkısıyla düzensiz olarak artıp azaldığı belirlenmiştir. \%0,4 Er katkılı ZnO filminin optik band aralığının diğer filmlere göre daha büyük olduğu gözlenmiştir.

Anahtar kelimeler: ZnO, Sol jel, SEM, XRD, Kubelka-Munk

\section{Effect of Erbium on Structural, Morphological and Optical Properties of Sol Gel Derived ZnO Film}

\begin{abstract}
Undoped and Erbium (Er) doped zinc oxide ( $\mathrm{ZnO}$ ) films were prepared on p-Si substrates by sol gel method using spin coating technique. The effect of Er dopant on the structural, morphological and optical properties of $\mathrm{ZnO}$ film was investigated by $\mathrm{X}$-ray diffractometer, scanning electron microscope (SEM) and UV-vis spectrophotometer, respectively. From X-ray diffraction (XRD) spectra, the films were crystallized in hexagonal wurtzite structure in zincite phase. The structural parameters such as grain size, dislocation density, lattice parameters, strain and stress were calculated. From the SEM images, it is seen that the film surfaces are well-coated, uniform, without cracks and pores. ImageJ program was used to investigate the average particle size, grain boundaries and the surface of the films. The optical properties were studied by diffuse reflectance spectra measured by UV-vis spectrophotometer and the optical band gap values were determined by differential reflectance and Kubelka-Munk theory. In both methods, it was determined the optical band gap value of $\mathrm{ZnO}$ film increases or decreases irregularly with the Er content. It was observed that the optical band gap of the $0.4 \%$ Er doped $\mathrm{ZnO}$ film was larger than the other films.
\end{abstract}

Key words: ZnO, Sol gel, SEM, XRD, Kubelka-Munk 


\section{Giriş}

Periyodik cetvelin II. grup elementlerinden biri olan çinko ( $\mathrm{Zn}$ ) ve VI. grup elementlerinden oksijenin $(\mathrm{O})$ oluşturduğu çinko oksit $(\mathrm{ZnO})$, elektronik ve optoelektronik devrelerin çoğunda kullanılan bir yariiletkendir. ZnO, n-tipi bir yariiletken olup, düşük elektriksel dirence, görünür bölgede yüksek optik geçirgenliğe ve geniş optik bant aralığına $\left(E_{g}=3,27 \mathrm{eV}\right.$, oda sıcaklığında) sahiptir $[1,2]$. $\mathrm{ZnO}$ bu özellikleri nedeniyle, elektronik ve optoelektronik uygulamalarda kullanılmaktadır [37].

$\mathrm{ZnO}$ filmleri kullanılacağı yere ve amaca uygun olarak farklı yöntemler kullanılarak elde edilebilir. $\mathrm{Bu}$ yöntemler saçtırma [8], kimyasal buhar depolama [9], moleküler demet epitaksi [10], gibi pahalı sistemler kullanılan yöntemlerin yanısıra, elektrokimyasal depolama [11], püskürtme [12] ve sol jel [13] gibi basit ve ucuz çözelti yöntemleri de olabilir. Film depolama parametrelerini değiştirerek ya da $\mathrm{ZnO}$ filmine uygun bir element katkılayarak, elde edilen $\mathrm{ZnO}$ filmlerinin morfolojik, yapısal, optik ve elektriksel özellikleri gibi fiziksel özellikleri değiştirilebilir.

Ulaşılabilir literatürdeki sol jel yöntemi ile hazırlanan çözeltiler kullanılarak spin kaplama tekniği ile elde edilen Erbiyum (Er) katkılı $\mathrm{ZnO}$ filmleri ile ilgili yapılan çalışmalarda kuartz ve cam alttaşlar üzerine elde edilmiş ve filmlerin fiziksel özelliklerinin karakterizasyonları yapılmıştır [14-18]. Bu çalışmanın amacı, silisyum (Si) alttaşlar üzerine farklı oranlarda Er katkısı ile ZnO filmlerini elde etmek ve Er katkı miktarının oluşturulan $\mathrm{ZnO}$ filminin fiziksel özellikleri üzerindeki etkilerini incelemektir. $\mathrm{Bu}$ amaç doğrultusunda filmler elde edildikten sonra yapısal, morfolojik ve optik özellikleri incelenerek optimum katkı miktarı belirlenecektir. $\mathrm{ZnO}$ filmine Er katkılayarak, katkısız $\mathrm{ZnO}$ filmine göre daha iyi fiziksel özelliklere sahip filmler elde edilmesi hedeflenmiştir.

\section{Materyal ve Metot}

\subsection{Alttaş temizliği}

Bu çalışmada, (100) yönelimli ve 0,1-10 $\Omega \mathrm{cm}$ özdirenç değerine sahip p-Si alttaşlar uygun boyutlarda kesilerek kullanılmıştır. Alttaşın iyi temizlenmesi, elde edilen filmin fiziksel özelliklerinin iyi olması açısından önemlidir. Bu nedenle önce p-Si alttaşlar, ultrasonik olarak temizlenip, azot gazı ile kurutulmuştur. Daha sonra alttaşların temizliği bir plazma temizleyici cihazı içerisinde argon gazı ortamında tamamlanarak, film üretimi için hazır hale getirilmiştir.

\section{2. Çözelti hazırlanması}

Çözelti hazırlama aşamasında, çinko kaynağı olarak çinko asetat dihidrat $\left(\mathrm{Zn}\left(\mathrm{CH}_{3} \mathrm{CO}_{2}\right)_{2} .2 \mathrm{H}_{2} \mathrm{O}\right.$; ZnAc; \%99,999; Sigma-Aldrich), sabitleyici olarak etanolamin $\left(\mathrm{NH}_{2}\left(\mathrm{CH}_{2}\right) 2 \mathrm{OH}\right.$; EA; $\geq \%$ 99; Merck), çözücü olarak 2-metoksietanol $\left(\mathrm{C}_{3} \mathrm{H}_{8} \mathrm{O}_{2} ; \geq \% 99,9\right.$; Sigma-Aldrich) ve Er katkı katk1 kaynağ1 olarak erbiyum(III) asetat hidrat $\left(\mathrm{Er}\left(\mathrm{CH}_{3} \mathrm{CO}_{2}\right)_{3} \cdot \mathrm{xH}_{2} \mathrm{O}\right.$; ErAc; $\geq \%$ 99,9; Sigma-Aldrich) kullanılmıștır. Katkı miktarları $(\% 0,2, \% 0,4, \% 0,6, \% 0,8, \% 1)$ kütlece hesaplanmıştır. Hazırlanan çözelti $60{ }^{\circ} \mathrm{C}$ de 2 saat karıştırılmış, süzgeç kağıdıyla süzülmüş ve sonuçta elde edilen şeffaf ve berrak çözeltiler hiç bekletilmeden hemen film üretimine geçilmiştir. 
Ulaşılabilir literatürdeki sol jel yöntemi ile hazırlanan çözeltiler kullanılarak spin kaplama tekniği ile elde edilen Er katkılı $\mathrm{ZnO}$ filmleri ile ilgili yapılan çalışmalara ait, çözelti parametreleri Tablo 1'de verilmiştir.

Tablo 1. Literatürde spin kaplama tekniği ile elde edilen Er katkılı ZnO filmlerinin çözelti parametreleri.

\begin{tabular}{|c|c|c|c|c|c|}
\hline Alttaş & Katkı Kaynağı & Çözücü & $\begin{array}{c}\text { Çözelti } \\
\text { karıştırma } \\
\text { sıcaklığı }\left({ }^{\circ} \mathrm{C}\right) / \\
\text { Süresi (sa) }\end{array}$ & $\begin{array}{c}\text { Katkı } \\
\text { konsantrasyonu } \\
(\%)\end{array}$ & Referans \\
\hline Kuartz & $\mathrm{Er}\left(\mathrm{CH}_{3} \mathrm{CO}_{2}\right)_{3} \cdot 4 \mathrm{H}_{2} \mathrm{O}$ & 2-Metoksietanol & $80 / 3$ & 0,05 & [14] \\
\hline Cam & $\mathrm{ErCl}_{3} \cdot 6 \mathrm{H}_{2} \mathrm{O}$ & Metanol & $---/ 2$ & $0 ; 0,2 ; 0,4 ; 0,6$ & {$[15]$} \\
\hline Kuartz & $\mathrm{Er}\left(\mathrm{CH}_{3} \mathrm{CO}_{2}\right)_{3} \cdot 4 \mathrm{H}_{2} \mathrm{O}$ & 2-Metoksietanol & $80 / 3$ & $0 ; 0,05 ; 0,5 ; 3$ & [16] \\
\hline Cam & $\mathrm{ErCl}_{3} \cdot 6 \mathrm{H}_{2} \mathrm{O}$ & 2-Metoksietanol & $60 / 1$ & $0 ; 1 ; 2 ; 3 ; 4 ; 5$ & [17] \\
\hline Cam & $\mathrm{Er}\left(\mathrm{CH}_{3} \mathrm{CO}_{2}\right)_{3} \cdot \mathrm{H}_{2} \mathrm{O}$ & 2-Metoksietanol & $40 / 2$ & $0 ; 0,5 ; 1 ; 5 ; 10$ & {$[18]$} \\
\hline
\end{tabular}

Tablo 1'de verilen çalışmaların hepsinde bu çalışmada olduğu gibi ZnO kaynağı olarak ZnAc ve sabitleyici olarak da etanolamin kullanılmıştır. Ancak bazı çalışmalarda farklı katkı kaynağı ve çözücü kullanılmıştır. Ayrıca Tablo 1'deki çalışmalarda, aslında aygıt yapımına bir hazırlık olması açısından oldukça önemli olan Si alttaş kullanılmağı da göze çarpmaktadır. Bu çalışmada seçilen parametrelerin diğerlerinden farklı ve özgün olmasına dikkat edilmiştir.

\subsection{Filmlerin elde edilmesi}

Temizlenen alttaşlar spin kaplama cihazındaki (LAUREL WS-400B-6NOO/LITE) numune tutucusuna yerleştirilerek, hazırlanan çözelti mikropipet yardımıyla damlatılmıştır. Ardından hemen 3000 rpm döndürme hızıyla 30 s süreyle döndürülerek, alttaş üzerinde sslak bir tabaka elde edilmiştir. $300{ }^{\circ} \mathrm{C}$ sıcaklığa ayarlanan kül firında (MTI marka KSL-1100X model) 10dk kurutulmuştur. Bu kaplama ve kurutma süreci aynı şekilde on kez tekrarlanmış ve en son olarak iyi kristallenmiş bir film elde edebilmek için, $600^{\circ} \mathrm{C}$ sıcaklıkta 1 sa süreyle filmler tavlanmıştır.

Ulaşılabilir literatürdeki sol jel yöntemi ile hazırlanan çözeltiler kullanılarak spin kaplama tekniği ile elde edilen Er katkılı $\mathrm{ZnO}$ filmleri ile ilgili yapılan çalışmalara ait, film depolama parametreleri Tablo 2'de verilmiştir.

Tablo 2. Literatürde spin kaplama tekniği ile elde edilen Er katkılı ZnO filmlerinin depolama parametreleri.

\begin{tabular}{ccccc}
\hline $\begin{array}{c}\text { Döndürme hızı } \\
(\mathbf{r p m}) / \text { süresi (s) }\end{array}$ & $\begin{array}{c}\text { Kurutma Sıcaklığı } \\
\left({ }^{\mathbf{0}} \mathbf{C}\right) / \text { Süresi }(\mathbf{d k})\end{array}$ & $\begin{array}{c}\text { Tavlama Sıcaklığı } \\
\left({ }^{\mathbf{0}} \mathbf{C}\right) / \text { Süresi (dk) }\end{array}$ & $\begin{array}{c}\text { Katman } \\
\text { Sayısı }\end{array}$ & Referans \\
\hline $3000 / 60$ & $280 / 10$ & $400 / 60 ;$ & 6 & {$[14]$} \\
$2500 / 30$ & $225 / 10$ & $600,800,1000 / 120$ & 15 & {$[15]$} \\
$3000 / 60$ & $280 / 10$ & $400,600,800,1000 / 120$ & 6 & {$[16]$} \\
--- & --- & $500,600 / 60$ & --- & {$[17]$} \\
$3000 / 30$ & $300 / 10$ & $550 / 60$ & 10 & {$[18]$} \\
\hline
\end{tabular}

Aynı çözelti parametreleri seçiminde olduğu gibi, film depolama parametrelerinin seçiminde de yapılan bu çalışmanın diğerlerinden ayırt edici olmasına dikkat edilmiştir. 


\subsection{Karakterizasyon}

Elde edilen filmlerin XRD spektrumları BRUKER D2 Phaser XRD cihazı kullanılarak $2 \theta=30^{\circ}-60^{\circ}$ arasında 0,02 derece adımlarla alınmıştır. Ölçümler monokromatik $\mathrm{Cu}_{\mathrm{K} \alpha}$ $(\lambda=1,54059 \AA)$ 1şını ile gerçekleştirilmiştir. Filmlerin yüzey morfolojileri ZEISS Ultraplus taramalı elektron mikroskobu (SEM) kullanılarak çalışılmıştır. Filmlerin diffüz yansıma spektrumları entegre küre ataçmanlı SHIMADZU UV-2450 UV-VIS spektrofotometre cihazı kullanılarak 200-900nm dalgaboyu aralığında ve $0,5 \mathrm{~nm}$ hassasiyet ile ölçülmüştür. Toz halde baryum sülfat $\left(\mathrm{BaSO}_{4}\right)$ referans olarak kullanılmıştır. Tüm ölçümler oda sıcaklığında yapılmıştır.

\subsection{Yapısal ve optik parametreler}

XRD spektrumu verileri kullanılarak, kristal yapının kristallenme boyutu $(D)$, dislokasyon yoğunluğu $(\delta)$, örgü sabitleri ( $a$ ve $c$ ), Kristal yapıdaki deformasyonu (strain, $\epsilon_{z}$ ) ve kristal yüzeyine paralel gerilimi (stress, $\sigma_{c}$ ) değerleri gibi yapısal parametreleri hesaplanabilir.

$D$ değeri aşağıda verilen Scherrer formülü kullanılarak hesaplanabilir.

$$
D=\frac{0,94 \lambda}{\beta \cos \theta}
$$

Burada; $\beta$ ilgili kristalin yarıpik genişliği, $\theta$ Bragg açısı ve $\lambda$ kullanılan X-ışınının dalgaboyudur [19].

Kristal yapıdaki çizgisel kusurlar (dislokasyon), malzemenin morfolojik özelliklerine ve taneciklerin oluşum ve boyutuna bağlı olup, malzemenin mukavemetini, sertlik ve sünekliğini doğrudan etkiler [20]. Bu kusurların miktarını belirlemek için, aşağıda verilen dislokasyon yoğunluğu ifadesi kullanılmaktadır [21].

$$
\delta=\frac{1}{D^{2}}
$$

Hekzagonal kristal yapının $a$ ve $c$ örgü parametreleri ile $d$ düzlemler arası mesafe arasındaki ilişki,

$$
\frac{1}{d^{2}}=\frac{4}{3}\left[\frac{h^{2}+h k+l^{2}}{a^{2}}\right]+\frac{l^{2}}{c^{2}}
$$

şeklindedir [22].

Kristal yapıdaki deformasyonu,

$$
\epsilon_{z}=\frac{d-d_{0}}{d_{0}}
$$

ifadesi ile verilmektedir [23]. Burada $d$ filme ait, $d_{0}(=2,60332 \AA, \mathrm{ZnO})$ bulk malzeme için standart düzlemler arası mesafedir. Hekzagonal örgü için, kristal yüzeyine paralel gerilimi: 


$$
\sigma_{c}=\left(C_{13}-\frac{C_{33}\left(C_{11}+C_{12}\right)}{2 C_{13}}\right) \epsilon_{z}
$$

şeklinde verilir [24]. Burada $C_{11}, C_{33}, C_{12}$ ve $C_{13}$ esneklik sabitleri olup sirasiyla $2,097 \times 10^{11} \mathrm{~N} / \mathrm{m}^{2}, 2,109 \times 10^{11} \mathrm{~N} / \mathrm{m}^{2}, 1,211 \times 10^{11} \mathrm{~N} / \mathrm{m}^{2}$ ve $1,051 \times 10^{11} \mathrm{~N} / \mathrm{m}^{2}$ değerlerindedir [25]. Denklem (5)'te esneklik sabitleri yerine yazılırsa $\sigma_{c}$ gerilimi,

$$
\sigma_{c}=-2,268 \times 10^{11} \epsilon_{z}
$$

şeklinde yazılabilir.

Opak filmlerin optik bant aralığını $\left(E_{g}\right)$ belirlemek için en iyi metotlardan biri difüz yansıma $(R)$ spektrumlarının belirlenmesidir. Filmlerin $E_{g}$ değerleri "diferansiyel yansıma" ya da "Kubelka-Munk Teorisi" yöntemleri kullanılarak hesaplanabilir.

Diferansiyel yansıma yönteminde, spektrumun dalgaboyuna göre birinci türevi alınır ve $d R / d \lambda-\lambda$ grafiği çizilir. Elde edilen bu grafikten $d R / d \lambda$ 'nın maksimum noktasındaki değere karşı gelen dalgaboyu değeri belirlenir. Bu dalgaboyuna karşı gelen enerji değeri, filmin $E_{g}$ değerini verecektir.

Kubelka-Munk teorisine göre, yansıma değerleri Kubelka-Munk fonksiyonları kullanılarak absorbsiyon değerlerine dönüştürülür. Kubelka-Munk fonksiyonu [26, 27],

$$
F(R)=\frac{(1-R)^{2}}{2 R}
$$

ile tanımlanır. Filmin $E_{g}$ değerinin belirlenebilmesi için aşağıdaki eşitlik kullanılabilir.

$$
\left(\frac{F(R) h v}{t}\right)^{2}=B\left(h v-E_{g}\right)
$$

Bu eşitlikte; $h v$ film üzerine gönderilen ışığın enerjisi, $t$ filmin kalınlığı, $B$ enerjiden bağımsız bir sabittir. $E_{g}$ 'yi belirlemek için $((F(R) h v) / t)^{2}-h v$ grafiği çizilir. Elde edilen eğri ekstrapole edilerek, doğrusal kısımların x eksenini kestiği noktadan $E_{g}$ değeri hesaplanabilir.

\section{Bulgular}

\subsection{Morfolojik özellikler}

Elde edilen katkısız ve Er katkılı ZnO filmlerinin SEM görüntüleri Şekil 1'de verilmiştir. Görüntüler incelendiğinde, filmlerin yüzeylerinde çatlak, gözenek ve boşlukların oluşmadan düzgün ve homojen bir yapının oluştuğu ve film yüzeylerinin nanoyapılı dairesel tanelerden oluştuğu görülmektedir. Nanotanelerin dairesel yapısının Er katkısı ile değişmediği, ancak tane boyutlarının değiştiği gözlenmiştir. Daha önce yapılan çalışmalarda da, bu çalışmada elde edilen katkısız ve Er katkılı ZnO filmlerinin yüzey morfolojilerine benzer SEM görüntüleri rapor edilmiştir [15, 28]. 
Şekil 1'de verilen filmlerin SEM görüntüleri ImageJ analiz programı yardımıyla analiz edilerek $\bar{D}$ tane boyutu değerleri hesaplanmış ve bu değerler Tablo 3 'te verilmiştir. En büyük ortalama tane boyutu ZEr-02 filmine aittir. ZnO filmine Er katkılanması ile tane boyutu önce artmış, katkı miktarının daha da artmasıyla tane boyutları küçülmüş yani, yapıda bozulmalar olmaya başlamıştır.
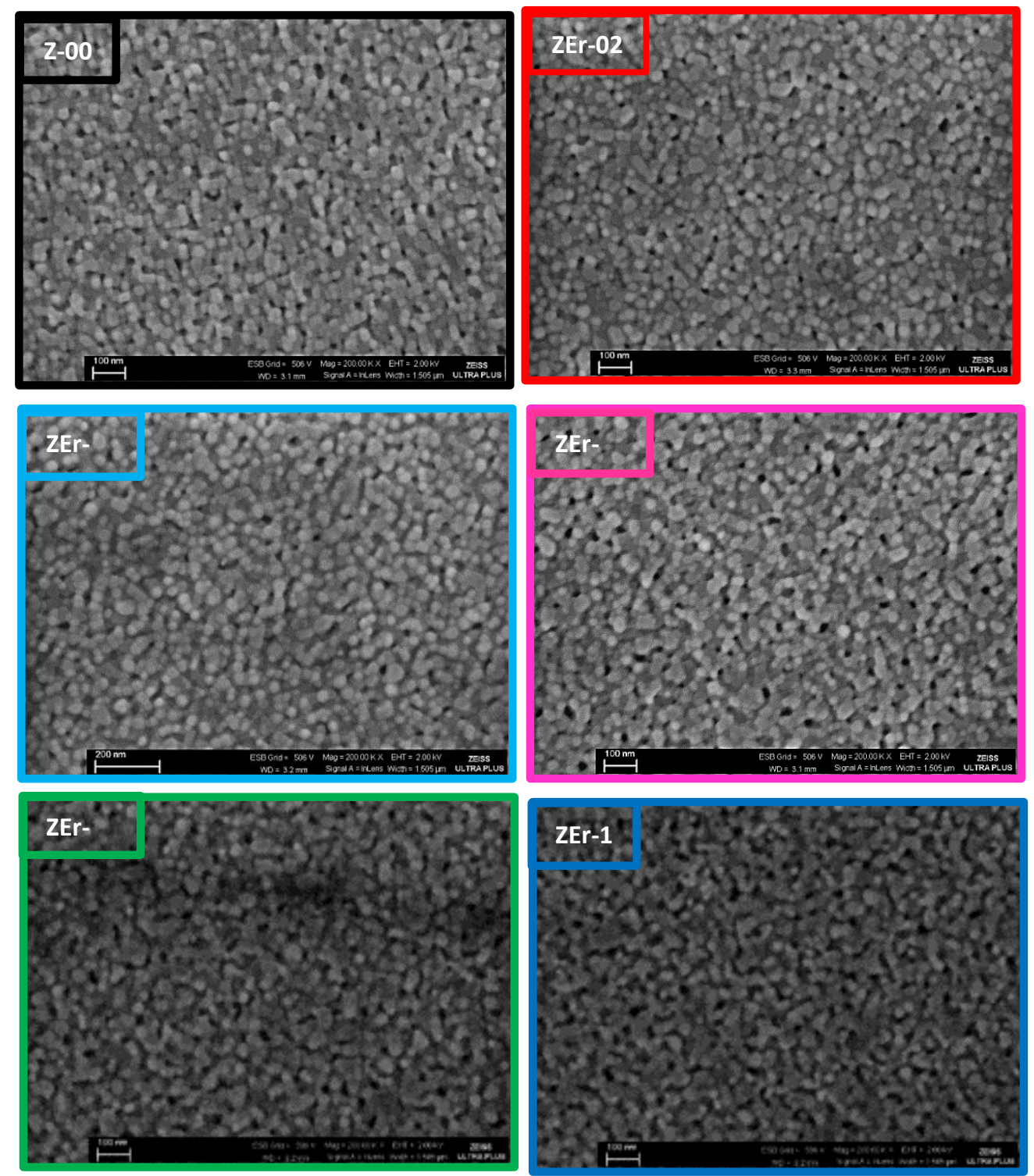

Şekil 1. Katkısız ve Er katkılı ZnO filmlerine ait SEM görüntüleri

Tablo 3. Elde edilen katkısız ve Er katkılı $\mathrm{ZnO}$ filmlerinin ortalama tane boyutları ve ortalama yükselti değerleri

\begin{tabular}{ccc}
\hline Film kodu & $\overline{\boldsymbol{D}}(\mathbf{n m})$ & $\overline{\boldsymbol{Y}}$ \\
\hline Z-00 & 21,3 & 106,4 \\
ZEr-02 & 28,2 & 96,0 \\
ZEr-04 & 24,0 & 99,9 \\
ZEr-06 & 22,8 & 103,3 \\
ZEr-08 & 21,0 & 65,4 \\
ZEr-1 & 19,3 & 63,5 \\
\hline
\end{tabular}


Şekil 2'de katkısız ve Er katkılı ZnO filmlerinin yüzey haritaları verilmiştir. Bu şekilden görüldüğü üzere, yüzey pürüzlülük oranları değişmiştir. ImageJ analiz programı yardımıyla hesaplanan yükseltilerin ortalama $\bar{Y}$ değerleri Tablo 3 'te verilmiştir. En küçük pürüzlülüğe sahip olan film ZEr-1 filmi $(\bar{Y}=63,5)$ olup, katkıya bağlı bir düzen görülmemiştir.
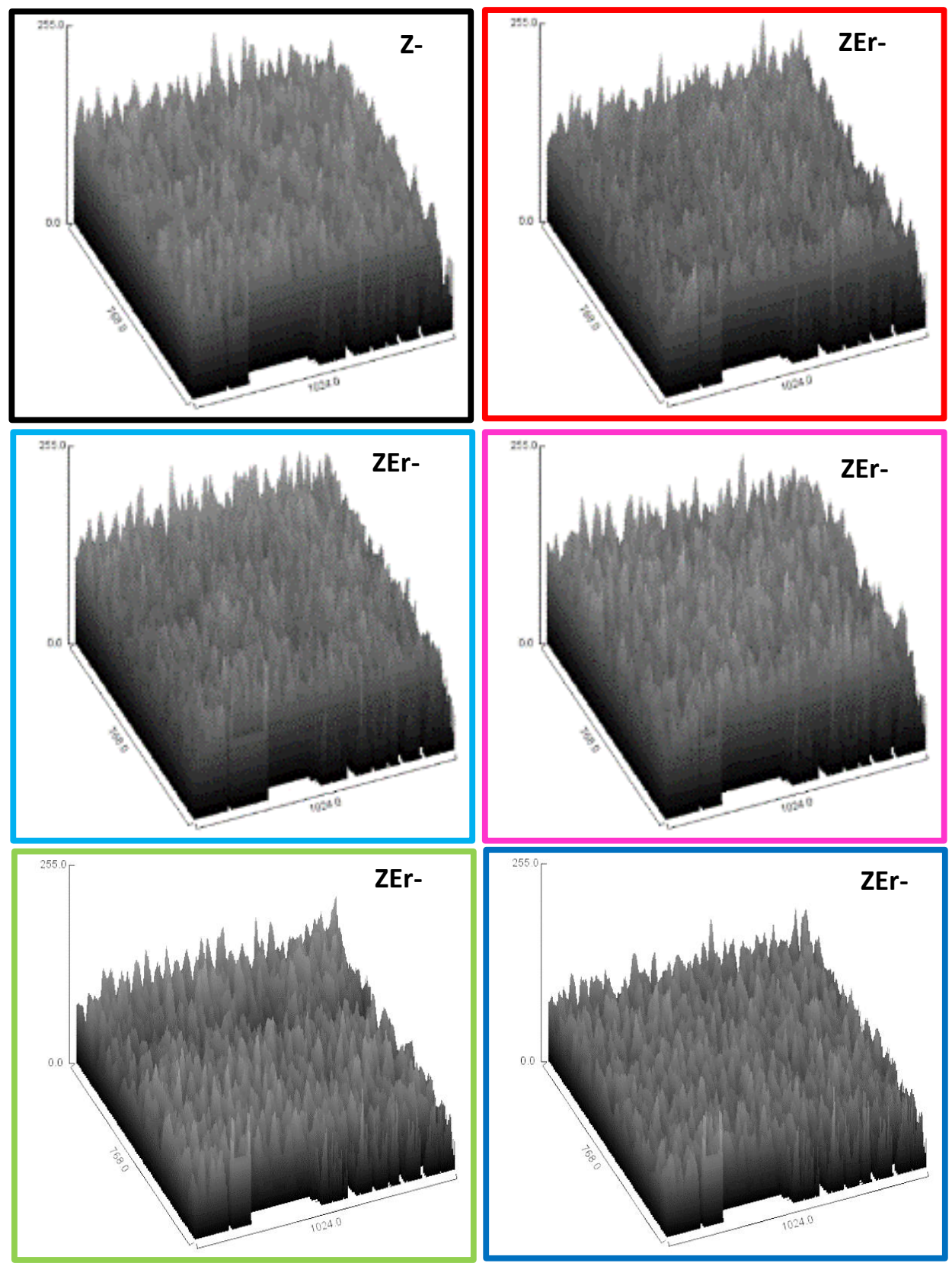

Şekil 2. Katkısız ve Er katk1lı ZnO filmlerine ait yüzey haritaları

Şekil 3'te katkısız ve Er katkılı ZnO filmlerinin tane sınırları verilmiştir. Film yüzeyindeki tanelerin benzer yapıda olduğu ve tane sınırlarının çok belirgin olduğu göze çarpmaktadır. Ayrıca, tane sınırlarının boyutlarının değiştiği görülmektedir. 

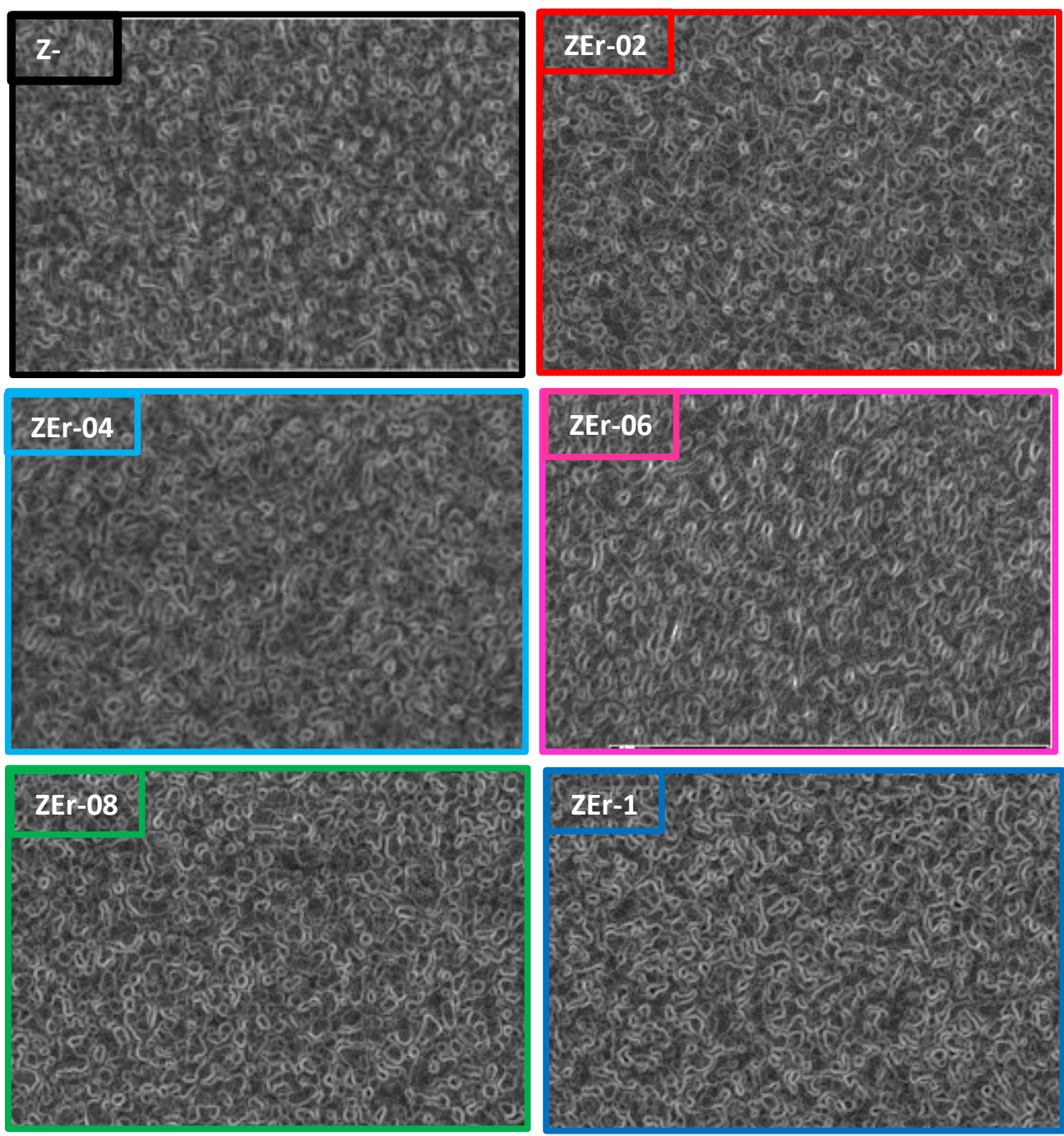

Şekil 3. Katkısız ve Er katkılı ZnO filmlerinin tane sınırları

Kumari ve ark. [15] elde ettikleri Er katkılı ZnO filmlerinin yüzey morfolojilerini SEM görüntülerini çekerek incelemişler, Er katkı miktarının film yüzeyinde değişikliklere sebep olduğunu rapor etmişlerdir. Tane boyutlarının katkı miktarına bağlı olarak $30 \mathrm{~nm}$ ile $60 \mathrm{~nm}$ arasında değiștiğini ve en büyük tanelerin \%0,4 Er katkılı $\mathrm{ZnO}$ filminde oluştuğunu ifade etmişlerdir. Katkı konsantrasyonun daha fazla artışı ile birlikte yapıda bozulmalar olduğunu ve tane boyutunun küçülmeye başladığını gözlemlemişlerdir.

\subsection{Yapısal özellikler}

Elde edilen katkısız ve Er katkılı ZnO filmlerine ait XRD spektrumları Şekil 4'te verilmiştir. Yapılan analiz sonucunda yapının hekzagonal wurtzite $\mathrm{ZnO}$ yapısına (JCPDS kart no:036-1451, Zinkit faz) ait tek faz olduğu belirlenmiştir. Katkı miktarı çok düşük düzeylerde olduğundan, Er katkı elementi ile ilgili $\mathrm{Er}_{2} \mathrm{O}_{3}$ ya da $\operatorname{Er}(\mathrm{OH})_{3}$ gibi fazlara ait herhangi bir pik gözlenmemiştir. Spektrumlarda gözlenen (100), (101), (102) ve (110) piklerinin (002) pikinin yanında çok çok küçük şiddete sahip olması nedeniyle 
$(<\% 1)$, diğer pikler ihmal edilmiştir. Bu nedenle sadece (002) pikinin gözlendiği ve tercihli yönelimin (002) olduğu söylenebilir.

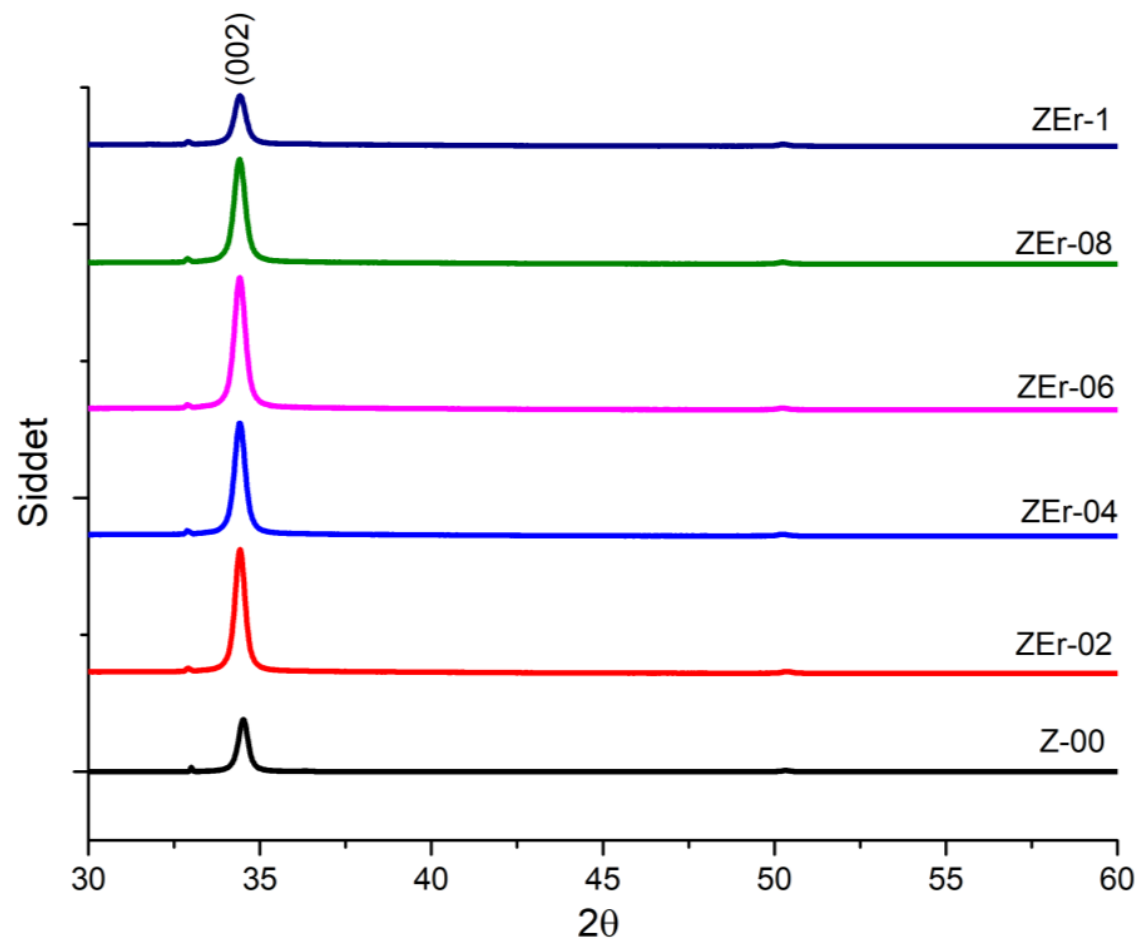

Şekil 4. Katkısız ve Er katkılı ZnO filmlerinin XRD spektrumları

Er katkı miktarının artışıyla önce (002) kırınım pikinin şiddeti artmış (ZEr-06 en şiddetli), katkı miktarı daha da arttırıldığında bu pik şiddeti azalmıştır. Bu trend literatür ile uyumludur. Kumari ve ark. [15] yaptıkları çalışmada, katkısız ve \%0,2, \%0,4, \%0,6 Er katkılı ZnO filmlerini elde etmişlerdir. Elde ettikleri bu filmlerin XRD spekrumlarından, elde ettikleri filmlerin hekzagonal yapıda ve (002) tercihli yönelimine sahip olduğunu rapor etmişlerdir. Er katkısı ile önce pik şiddetinin arttığını (en yüksek \%0,4 Er katkılı ZnO filminde), katkının daha da artmasıyla pik şiddetinin yeniden azaldığını ve kristal yapının bozulduğunu gözlemlemişlerdir. Choi ve Ma [29] katkısız ve \%1, \%2, \%3 Er katk1lı $\mathrm{ZnO}$ filmlerini püskürtme yöntemini kullanarak $\mathrm{MgO}$ alttaşlar üzerine elde etmişlerdir. Filmlerin XRD spekrtrumlarından, $\mathrm{ZnO}$ filmine $\% 1 \mathrm{Er}$ katkılandığında pik şiddetinin arttığını, katkı oranının arttırılmasıyla pik şiddetinde azalma olduğunu rapor etmişlerdir. Ayrıca, Er katkısına ait fazla ilgili herhangi bir pike rastlanmadığını da belirtmişlerdir. Elde ettikleri tüm filmlerin tercihli yöneliminin (002) düzleminde olduğunu ifade etmişlerdir.

Elde edilen filmlere ait XRD spektrumlarındaki (002) piklerinin $\beta$ yarıpik genişliği Er katkı miktarı artınca önce daralmış (ZEr-02 en dar), daha sonra katkı arttıkça $\beta$ değeri yeniden büyümüştür (Tablo 4). Filmlerin (002) yönelimindeki $D$ ve $\delta$ değerleri, sirasıyla Denklem (1) ve (2) kullanılarak hesaplanmış ve Tablo 4'te verilmiştir. Elde edilen filmlerin kristallenme boyutları 21-24nm aralığında değişmektedir. En büyük kristallenme boyutu ve en küçük dislokasyon yoğunluğu ZEr-02 filminde oluşmuştur. Küçük katkı miktarlarında kristallenme boyutu artarken, katkının daha da artmasıyla birlikte azalmaya başlamıştır. $\mathrm{Er}^{+3}(1,00 \AA)$ ve $\mathrm{Zn}^{+2}(0,74 \AA)$ arasındaki iyonik yarıçap farkı çok büyüktür. $\mathrm{Zn}^{+2}$, nin kristal örgü içerisindeki yerine $\mathrm{Er}^{+3}$ iyonu yerleştiğinde bu 
durum kristal örgüde bozulmalara neden olabilir. Elde edilen bu sonuçlar literatür ile uyum içerisindedir [15,29]

Elde edilen filmlerin XRD spektrumlarında sadece (002) piki olması nedeniyle, $a$ örgü parametresi hesaplanamamış, sadece $c$ örgü parametreleri Denklem (3) kullanılarak hesaplanabilmiş ve hesaplanan değerler Tablo 4'te verilmiştir. En büyük $c$ değeri ZEr02 filmine aittir.

Elde edilen filmlerin kristal yapısına ait $\epsilon_{z}$ deformasyonu Denklem (4) ve $\sigma_{c}$ gerilimi Denklem (6) kullanılarak hesaplanmış ve Tablo 4 'te verilmiştir.

Tablo 4. Elde edilen katkısız ve Er katkı1ı ZnO filmlerinin (002) yönelimine ait yapısal parametreleri

\begin{tabular}{ccccccccc}
\hline Film & $\mathbf{2} \boldsymbol{\theta}$ & $\boldsymbol{d}(\boldsymbol{\AA})$ & $\left.\boldsymbol{\beta} \mathbf{(}^{\mathbf{0}}\right)$ & $\boldsymbol{D}$ & $\boldsymbol{\delta}\left(\mathbf{m}^{-\mathbf{2}}\right)$ & $\boldsymbol{c}(\boldsymbol{\AA})$ & $\boldsymbol{\epsilon}_{\mathbf{z}} \mathbf{x 1 0}$ & $\boldsymbol{\sigma}_{\boldsymbol{c}}\left(\mathbf{N m}^{-\mathbf{2}}\right)$ \\
\hline Z-00 & 34,4 & 2,60311 & 0,37 & 21,9 & 2,09 & 5,2062 & $-8,14$ & 1,85 \\
ZEr-02 & 34,4 & 2,60361 & 0,34 & 24,1 & 1,72 & 5,2072 & 11,00 & $-2,49$ \\
ZEr-04 & 34,4 & 2,60313 & 0,35 & 23,5 & 1,81 & 5,2063 & $-7,30$ & 1,66 \\
ZEr-06 & 34,4 & 2,60313 & 0,35 & 23,0 & 1,88 & 5,2063 & $-7,18$ & 1,63 \\
ZEr-08 & 34,4 & 2,60342 & 0,37 & 21,9 & 2,08 & 5,2068 & 3,80 & $-0,86$ \\
ZEr-1 & 34,4 & 2,60300 & 0,38 & 21,4 & 2,17 & 5,2060 & $-12,2$ & 2,77 \\
\hline
\end{tabular}

\subsection{Optik özellikler}

Katkısız ve Er katkılı ZnO filmlerinin difüz yansıma spekturumları Şekil 5'te verilmiştir. Filmlerin yansıma spektrumlarında 350-450nm dalgaboylarında yayvan bir pik göze çarpmaktadır. Pikin pozisyonu Er katkısı ile değişmektedir. $\mathrm{Bu}$ da $\mathrm{ZnO}$ filmlerinin optik band aralıklarının Er katkı miktarı ile değiştiğini göstermektedir. Ayrıca katkı miktarı ile yansıma değerlerinin maksimumları da \%45 ile \%80 arasında değişim göstermektedir.

Elde edilen filmlerin $E_{g}$ değerini belirleyebilmek için kullanılan diferansiyel yansıma yönteminde, diffüz yansıma spektrumunun dalgaboyuna karşı birinci türevi $(d R / d \lambda)$ alınmıştır. Elde edilen bu türev değerleri ile dalgaboyuna karşılık bir grafik çizilmiştir (Şekil 5). Bu eğrilerin maksimum noktalarına karşılık gelen dalgaboyu değerleri sirasiyla $378 \mathrm{~nm}, 379 \mathrm{~nm}, 375,5 \mathrm{~nm}, 376 \mathrm{~nm}, 376,5 \mathrm{~nm}, 377 \mathrm{~nm}$ 'dir. Bu dalgaboylarına karşılık gelen enerji değerleri hesaplanmış ve Tablo 5'te verilmiştir. Hesaplanan $E_{g}$ değerlerinin, $\mathrm{ZnO}$ filmine Er katkılanmasıyla azaldığı görülmektedir. Katkılı filmler arasında ise, $E_{g}$ değerinin önce arttığı ve daha sonra yeniden azaldığı görülmektedir. En yüksek $E_{g}$ değerine sahip film ZEr-04 filmidir. Bu değişimin nedeni, katkı atomlarının optik band aralığı içine yerleşerek, bant kuyruklarının oluşmasına sebep olmasına atfedilebilir. Elde edilen $E_{g}$ değerleri literatür ile uyum içerisindedir [16]. 

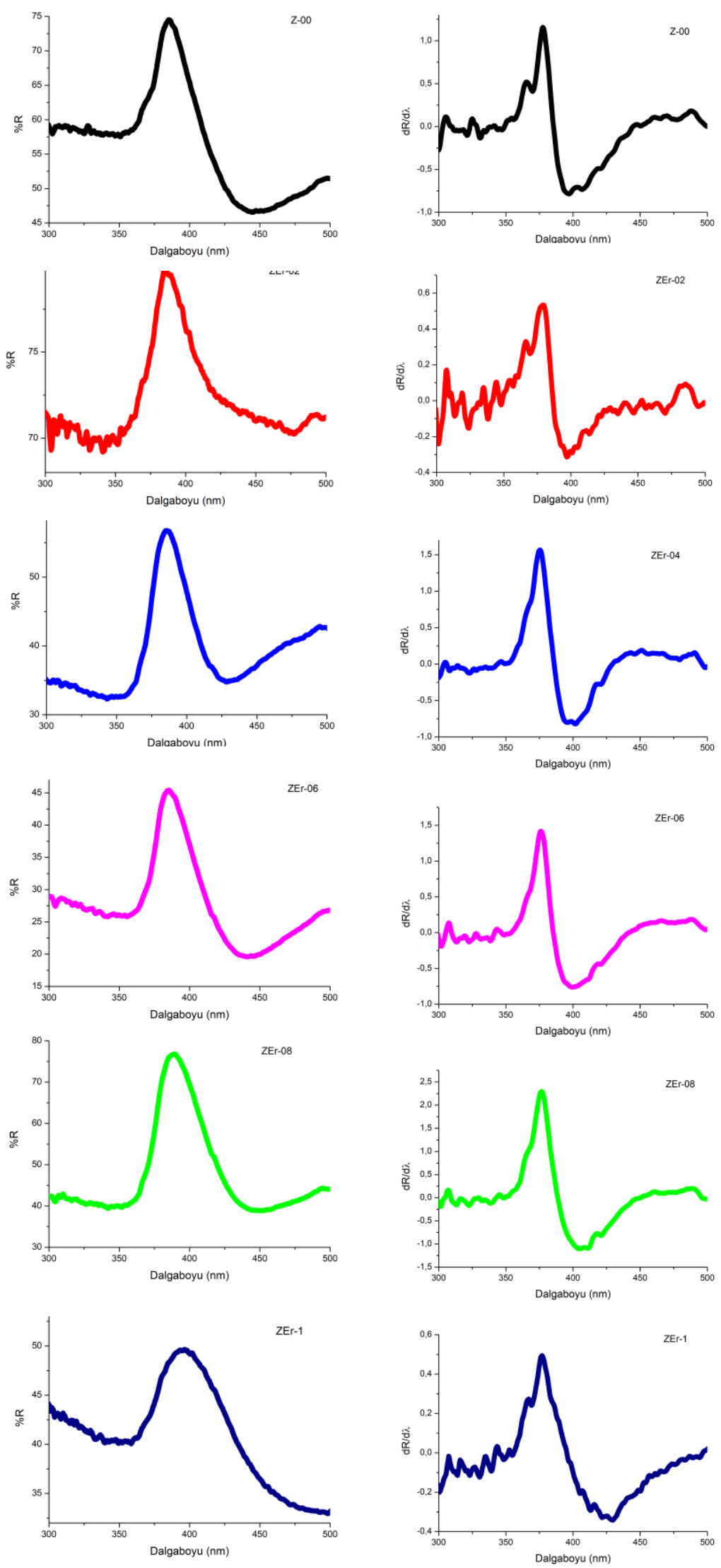

Şekil 5. Katkısız ve farklı oranlarda Er katkılı ZnO filmlerinin difüz yansıma spektrumları (sol) ve dalgaboyuna karşı çizilen $\mathrm{dR} / \mathrm{d} \lambda$ grafikleri (săg) 
Tablo 5. Elde edilen katkısız ve Er katkılı ZnO filmlerinin diferansiyel yansıma ve Kubelka-Munk teorisi kullanılarak hesaplanan $\mathrm{E}_{\mathrm{g}}$ değerleri

\begin{tabular}{ccc}
\hline Film kodu & $\begin{array}{c}\boldsymbol{E}_{\boldsymbol{g}}(\mathbf{e V}) \\
\boldsymbol{d} \boldsymbol{R} / \boldsymbol{d} \boldsymbol{\lambda}\end{array}$ & $\begin{array}{c}\boldsymbol{E}_{\boldsymbol{g}}(\mathbf{e V}) \\
\text { Kubelka-Munk }\end{array}$ \\
\hline Z-00 & 3,286 & 3,213 \\
ZEr-02 & 3,277 & 3,217 \\
ZEr-04 & 3,308 & 3,269 \\
ZEr-06 & 3,303 & 3,233 \\
ZEr-08 & 3,299 & 3,256 \\
ZEr-1 & 3,294 & 3,221 \\
\hline
\end{tabular}
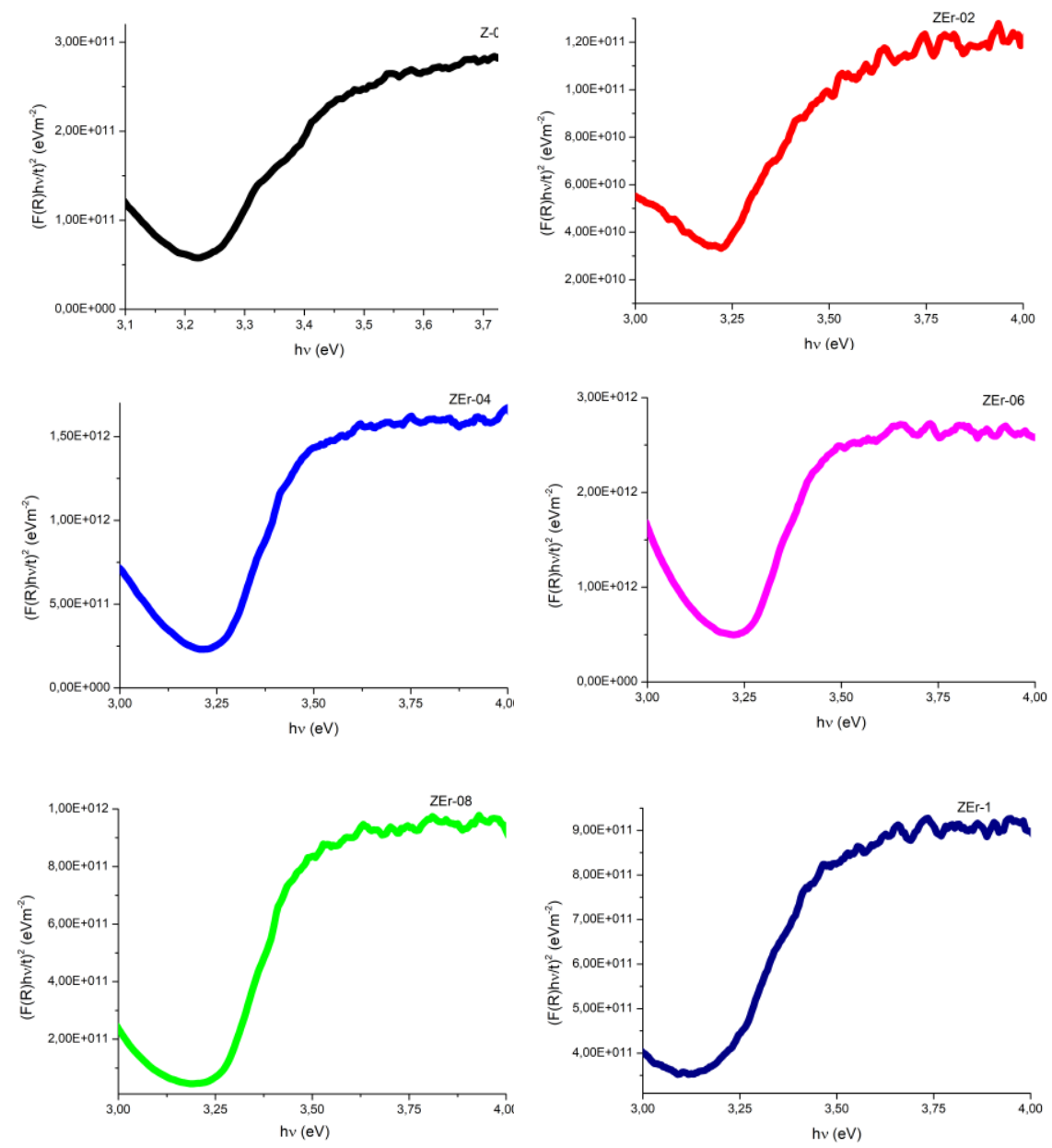

Şekil 6. Katkısız ve farklı oranlarda Er katkılı ZnO filmlerinin Kubelka-Munk grafikleri

Diğer yöntemde ise, Denklem (7) ile verilen Kubelka-Munk fonksiyonu yardımıyla difüz yansıma değerleri absorpsiyon değerlerine dönüştürülmüştür. Elde edilen bu değerler kullanılarak Denklem (8) kullanılarak filmlerin $E_{g}$ değerlerini belirleyebilmek için $(F(R) h v) / t)^{2}-h v$ grafiği çizilmiş (Şekil 6) ve $E_{g}$ değerleri hesaplanmıştır (Tablo 5). Hesaplanan $E_{g}$ değerlerinin katkı ile düzensiz bir şekilde azalıp arttığı görülmektedir. En yüksek $E_{g}$ değerine sahip film, diğer yöntemde olduğu gibi, ZEr-04 filmidir. 


\section{Sonuç ve Yorum}

Sol jel yöntemi ile hazırlanan çözeltiler kullanılarak, $p$-Si alttaşlar üzerine spin kaplama tekniği ile elde edilen katkısız ve $\mathrm{Er}$ katkılı $\mathrm{ZnO}$ filmlerinin fiziksel özellikleri araştırılmıştır. Filmlerin morfolojik özellikleri SEM görüntüleri çekilerek incelenmiştir. Film yüzeylerinin boşluksuz ve homojen kaplandığ 1 , dairesel nanotanelerden oluştuğu gözlenmiştir. SEM görüntülerinin ImageJ analiz programı kullanılarak, yüzey haritaları ve tane sınırları çizilerek, ortalama tane boyutları ve yükselti değerleri belirlenmiştir. Filmlerin XRD spektrumlarından, tek fazda $(\mathrm{ZnO})$ ve (002) yönelimine sahip oldukları görülmüştür. Kristallenme boyutları 21-24nm aralığında değişmektedir. XRD ve SEM analizleri sonucunda, en büyük kristallenme boyutuna sahip olan filmin ZEr-02 filmi olduğu belirlenmiştir. $\mathrm{Er}^{+3}(1,00 \AA)$ ve $\mathrm{Zn}^{+2}(0,74 \AA)$ arasındaki iyonik yarıçap farkı çok büyük olduğu için, katkı miktarı arttıkça oluşan kristal yapıda bozulmalar olmuştur. Filmlerin difüz yansıma spektrumları çekilmiş ve bu spektrumlardan yararlanılarak hem diferansiyel yansıma hem de Kubelka-Munk yöntemleri ile filmlerin optik band aralıkları hesaplanmıştır. Elde edilen filmlerin hesaplanan $E_{g}$ değerleri incelendiğinde katk1 ile beraber $E_{g}$ değerinin değiştiği görülmüştür, ancak bu değişim çok küçük miktarlarda olmuştur. Her iki yöntemde de en yüksek $E_{g}$ değeri ZEr-04 filminde elde edilerken, en küçük $E_{g}$ değeri ZEr-02 filminde elde edilmiştir. Diferansiyel yansıma yöntemiyle $30 \mathrm{meV}$ değerinde ve Kubelka-Munk teorisi ile $50 \mathrm{meV}$ değerinde bir değişim gözlenmiştir. Katkı ile birlikte $E_{g}$ değerlerinin düzensiz bir şekilde azalıp arttı̆̆ görülmüştür. $E_{g}$ değerinin bu şekilde değişiminin nedeni katkı atomlarının optik bant aralığı içine yerleşerek bant kuyrukları oluşturmasına atfedilebilir. Özellikle $p$-n heteroeklem uygulamalarında, yüzeyin iyi kaplanması ve pürüzlülüğü oldukça önemlidir. $\mathrm{Bu}$ çalışmada elde edilen bütün film yüzeylerinin boşluksuz olarak kaplanması aygıt uygulamalarında kullanılabilir olduklarının bir göstergesidir. Sonraki çalışmalarda, elde edilen bu filmler ile $p$-Si/n-ZnO:Er heteroeklemlerinin fabrikasyonunun yapılması ve elektriksel karakterizasyonlarının yapılarak diyot parametrelerinin araştırılması planlanmıştır.

\section{Teşekkür}

$\mathrm{Bu}$ çalışma, Anadolu Üniversitesi Bilimsel Araştırma Komisyonu $1501 \mathrm{F032}$ no'lu lisansüstü projesi tarafından desteklenmiş ve Gonca Ilgu Büyük'ün doktora tezinin bir parçası olarak yapılmıştır.

\section{Kaynakça}

[1] H. Morkoç and Ü. Özgür, Zinc Oxide: Fundamentals, Materials and Device Technology. Wiley Company, Germany, 2009.

[2] G. Ilgu, Y. Caglar, S. Ilican, M. Caglar, S. Ruzgar, "The effect of sol concentration on the structural and electrical parameters of nanostructure $\mathrm{ZnO}$ films by sol gel dip coating," J. Nanoelectron. Optoe., 9, 622-627, 2014.

[3] M. Raja, N. Muthukumarasamy, D. Velauthapillai, R. Balasundaraprabhu, S. Agilan, and T. S. Senthil, "Studies on bundle like ZnO nanorods for solar cell applications," Solar Energy, 106, 129135, 2014.

[4] L. Zhu and W. Zeng, "Room-temperature gas sensing of ZnO-based gas sensor: A review," Sensor. Actuat. A-Phys., 267, 242-261, 2017.

[5] T. Ates, C. Tatar, and F. Yakuphanoglu, "Preparation of semiconductor $\mathrm{ZnO}$ powders by sol gel method: Humidity sensors," Sensor. Actuat. A-Phys., 190, 153-160, 2013.

[6] S. Ilican, K. Gorgun, Y. Caglar and M. Caglar, "Influence of irradiation time on structural, morphological properties of ZnO-NRs films deposited by MW-CBD and their photodiode applications," J. Nanomaterials, 2017, 1-12, 2017. 
[7] Y. Caglar, M. Caglar, S. Ilican, S. Aksoy and F. Yakuphanoglu, "Effect of channel thickness on the field effect mobility of ZnO-TFT fabricated by sol gel process," J. Alloys Compound., 621, 189-193, 2015.

[8] R. S. Gonçalves, P. Barrozo, G. L. Brito, B. C. Viana, and F. Cunha, "The effect of thickness on optical, structural and growth mechanism of $\mathrm{ZnO}$ thin film prepared by magnetron sputtering," Thin Solid Films, 661, 40-45, 2018.

[9] L. Phan, S. C. Yu, R. Vincent, N. H. Dan, and W. S. Shi, "Photoluminescence properties of various CVD-grown ZnO nanostructures,” J. Lumin., 130, 1142-1146, 2010.

[10] C. Su, Y. M. Lu, Z. Z. Zhang, C. X. Shan, B. Yao, B. H. Li, D. Z. Shen, J. Y. Zhang, D. X. Zhao, and X. W. Fan, "The optical properties of $\mathrm{ZnO} / \mathrm{ZnMgO}$ single quantum well grown by P-MBE," Appl. Surf. Sci., 254, 7303-7305, 2008.

[11] A. Arslan, E. Hur, S. Ilican, Y. Caglar, and M. Caglar, "Controlled growth of c-axis oriented ZnO nanorod array films by electrodeposition method and characterization," Spectrochim. Acta A, 128, 716-723, 2014

[12] M. Imai, M. Watanabe, H. Tominaga, K. Yoshino, Y. Ogomi, Q. Shen, T. Toyoda, T. Minemoto, and S. Hayase, "Growth mechanism of $\mathrm{ZnO}$ thin films grown by spray pyrolysis using diethylzinc solution,” Phys. Status Solidi A., 215, 1700406, 2018.

[13] D. Aryanto, W. N. Jannah., Masturi, T. Sudiro, A. S. Wismogroho, P. Sebayang, Sugianto, and P. Marwoto, "Preparation and structural characterization of $\mathrm{ZnO}$ thin films by sol-gel method," $J$. Phys: Conf. Series, 817, 012025, 2017.

[14] F. Ran, L. Miao, S. Tanemura, M. Tanemura, Y. Cao, S. Tanaka, and N. Shibata, " Effect of annealing temperature on optical properties of Er-doped $\mathrm{ZnO}$ films prepared by sol-gel method," Mater. Sci. Eng. B, 148, 35-39, 2008.

[15] V. Kumari, V. Kumar, B. P. Malik, and R. M. Mehra, "Devendra Mohan Nonlinear optical properties of erbium doped zinc oxide (EZO) thin films," Opt. Commun., 285(8), 2182-2188, 2012.

[16] L. Miao, S. Tanemura, L. Zhao, X. Xiao, and X. T. Zhang, "Ellipsometric studies of optical properties of Er-doped $\mathrm{ZnO}$ thin films synthesized by sol-gel method," Thin Solid Films, 543, 125129, 2013.

[17] R. Vettumperumal, S. Kalyanaraman, and R. Thangavel, "Optical constants and near infrared emission of Er doped ZnO sol-gel thin films," J. Lumin., 158, 493-500, 2015

[18] S. Ilican, "Structural, optical and electrical properties of Erbium-Doped ZnO thin films Prepared by spin coating method," J. Nanoelectron. Optoe., 11(4), 465-471, 2016.

[19] B. D. Cullity, Elements of X-Ray Diffraction. Addison-Wesley Publishing Company Inc., United States of America, 1956.

[20] A. S. Hassanien, A. A. Akl, and A. H. Sáaedi, " Synthesis, crystallography, microstructure, crystal defects, and morphology of $\mathrm{Bi}_{\mathrm{x}} \mathrm{Zn}_{1-\mathrm{x}} \mathrm{O}$ nanoparticles prepared by sol-gel technique," Cryst. Eng. Comm., 20, 1716-1730, 2018.

[21] G. K. Williamson and R. E. Smallman, "Dislocation densities in some annealed and cold-worked metals from measurements on the X-Ray Debye-Scherrer spectrum," Philosophical Magazine, 1(1), 34-45, 1956.

[22] C. Kittel, Introduction to Solid State physics. (8. Bask1). John Wiley and Sons, Inc., United States of America, 2005.

[23] M. E. Fitzpatrick, A. T. Fry, P. Holdway, F. A. Kandil, J. Shackleton, and L. Suominen, Determination of Residual Stresses by X-ray Diffraction (Issue 2). Measurement Good Practice Guide No. 52, United Kingdom, 2005.

[24] H. Hong, J. Huang, H. He, Z. Fan, and J. Shao, "Influence of different post-treatments on the structure and optical properties of zinc oxide thin films." Appl. Surf. Sci., 242, 346-352, 2005.

[25] T. B. Bateman, "Elastic moduli of single-crystal zinc oxide,” J. Appl. Phys., 33, 3309-3312, 1962.

[26] A. E. Morales, E. S. Mora, and U. Pal, "Use of diffuse reflectance spectroscopy for optical characterization of un-supported nanostructures," Rev. Mex. Fisica S., 53(5), 18-22, 2007.

[27] V. Senthilkumar, P. Vickraman, and R. Ravikumar, " Synthesis of fluorine doped tin oxide nanoparticles by sol-gel technique and their characterization,” J. Sol-Gel Sci. Technol., 53(2), 316$321,2010$.

[28] S. Q. Li, C. B. Yao, Y. Cai, Y. Han, K. X. Zhang, X. Wen, H. T. Yin, Q. H. Li, and W. J. Sun, "Nonlinear absorption properties and excitedstate charge-transfer dynamics of Er doped ZnO films," Opt. Mater. Exp., 8(11), 3262-3276, 2018.

[29] M. H. Choi and T. Y. Ma, "Erbium concentration effects on the structural and photoluminescence properties of ZnO:Er films,” Mater. Lett., 62, 1835-1838, 2008. 